\title{
Climate change and the outdoor regional living plant collections: an example from mainland Portugal
}

\author{
Tiago Monteiro-Henriques • M. Dalila Espírito-Santo
}

Received: 20 August 2009/Accepted: 10 May 2010/Published online: 20 May 2010

(C) Springer Science+Business Media B.V. 2010

\begin{abstract}
Climate change threatens not only plant species occurring naturally, but also impacts on regional living plant collections, which play an important role in ex situ conservation strategies. In the last few years, several global circulation models have been used to predict different global climate change scenarios. Due to their coarse resolutions, and while more detailed regional approaches are not available, downscaling techniques have been proposed, as a very simple first approach to increase detail. We analysed seven sites on mainland Portugal with potential for species conservation (four botanic gardens and three universities), in the light of downscaled climate change scenarios, using an environmental envelope approach and a predefined bioclimatic neighbourhood for each site. Thresholds for the bioclimatic neighbourhood were based on Rivas-Martínez's Bioclimatic Classification of the Earth. For each site, the expected geographical shift of its original bioclimatic neighbourhood (1950-2000) was mapped for 2020, 2050 and 2080. Analysing those shifts enabled us to delineate knowledge-transfer paths between sites, according to the analysed scenarios. We concluded that, according to the Intergovernmental Panel on Climate Change A2 scenario, all considered sites will be outside the predefined bioclimatic neighbourhood by 2080, while according to the B2 scenario all of them will be inside that neighbourhood, although sometimes marginally so. Therefore, the implementation of global sustainability measures as considered in the B2 scenario family can be of great importance in order to delay significantly the impacts of climate change, giving extra time for the adaptation of the outdoor regional living plant collections.
\end{abstract}

Keywords Bioclimatic envelope modelling - Downscaled climate change scenarios . Ex situ conservation $\cdot$ Global warming $\cdot$ Knowledge-transfer paths

T. Monteiro-Henriques $(\bowtie) \cdot$ M. D. Espírito-Santo

Centro de Botânica Aplicada à Agricultura, Instituto Superior de Agronomia, Technical University

of Lisbon (TULisbon), Tapada da Ajuda, 1349-017 Lisbon, Portugal

e-mail: tmh@isa.utl.pt

M. D. Espírito-Santo

e-mail: dalilaesanto@isa.utl.pt 


\section{Introduction}

Several studies point out that climate change can threaten numerous plant species (Davis and Shaw 2001; Thuiller et al. 2005), illustrating the importance of ex situ conservation strategies to ensure persistence of biodiversity in the long term. However, changes in climate due to global warming are already taking place locally and globally, being imperative to improve our understanding of how future climate will affect biodiversity (Araújo and Rahbek 2006; Botkin et al. 2007).

Climate is undoubtedly the key limiting factor of species distributions at macroecological scales (Box 1981; Woodward and Williams 1987), therefore, models based on the present relationships between climate and species are expected to supply a first approach to predict the impacts of climate change on species distributions, although several limitations are known and must be taken into account (Pearson and Dawson 2003, 2004; Hampe 2004; Araújo et al. 2005a, b; Araújo and Luoto 2007; Brook et al. 2008; Fitzpatrick and Hargrove 2009; Felton et al. 2009).

One of the most striking limitations of current species-climate predictions is the fact that migration and land-use interactions are not fully taken into account in such models (Thuiller et al. 2008). The complexity of migration processes, dependent on a great number of fundamental variables, discourages their proper treatment. However, as human presence has significantly fragmented natural spaces in certain regions, species' movements might already be compromised; consequently, discussion on managed migration has been started (McLachlan et al. 2007; Chapin III et al. 2007). The matter is controversial (Hunter 2007; Holmes 2007; Mueller and Hellmann 2008; Appell 2009) although it is a possible lastalternative for biodiversity conservation, in tight dependence of correctly implemented ex situ conservation strategies (Hannah 2008; Richardson et al. 2009).

Botanic gardens have long been relevant in ex situ conservation, maintaining seed banks and living plant collections, actively participating in the conservation of threatened species and in species recovery programmes (see Guerrant and Pavlik 1997, for some examples). Of crucial importance is the establishment of collections of living plants coming from the same region where the garden is located (regional living plant collections), where a greater success in the species fostering and maintenance is expected. This practice is encouraged by the Global Strategy for Plant Conservation, which grew out of the Convention on Biological Diversity. Target viii of the referred Strategy recommends that at least $60 \%$ of threatened plant species should be accessible in ex situ collections, preferably in their home country (Secretariat of the Convention on Biological Diversity 2003). Pyšek et al. (2009, p. 52) calculated that the greater part $(39.9 \%)$ of naturalised plant taxa in Europe were firstly used as ornamental plants; therefore, regional collections are also most appropriate for botanic gardens within natural areas, where the use of exotic plants represents an additional risk, as they can become invasive.

Global warming will affect not only the naturally occurring communities but also outdoor regional living plant collections can suffer its consequences. With the present study, we intended to assess the magnitude of future climate change, according to the available climate change scenarios, focusing on the existing Portuguese outdoor regional living plant collections with potential to take part in ex situ conservation strategies.

\section{Methods}

Seven sites within mainland Portugal, with potential to realize ex situ conservation, have been chosen (four botanic gardens and three universities), namely: (1) Vila Real (Jardim 
Botânico da Universidade de Trás-os-Montes e Alto Douro-JBUTAD); (2) Oporto (Jardim Botânico da Universidade do Porto-JBUP); (3) Coimbra (Jardim Botânico da Universidade de Coimbra-JBUC); (4) Lisbon (Jardim Botânico da Ajuda and Jardim Botânico da Universidade de Lisboa-JBA); (5) Castelo Branco (Escola Superior Agrária, Instituto Politécnico de Castelo Branco-ESACB); (6) Évora (Universidade de Évora, Mitra-UE); (7) Faro (Universidade do Algarve-UA). For convenience, all sites will be referred to as botanical collections within this text. These sites should ensure a good coverage of the bioclimatic conditions present in mainland Portugal.

Three bioclimatic indices with known influence on vegetation (Gavilán 2005) were calculated for mainland Portugal: Compensated Thermicity Index (CTI), Ombrothermic Index (OI), and Simple Continentality Index (SCI); see Rivas-Martínez (2007) and below for further information.

All calculations were done using Map Algebra instructions within ESRI ArcMap ${ }^{\mathrm{TM}} 9.2$ SP5 geographical information system. Base data employed for indices calculations were downloaded from WorldClim data portal (Hijmans et al. 2006) where high resolution data for 'current' (1950-2000) climatic conditions (Hijmans et al. 2005) and downscaled future global climate change scenarios are available. Downscaling techniques have been suggested as a simple first approach to increase detail while high resolution regional approaches are not available. Downscaling procedures relied on 'current' WorldClim data for calibration; full description and limitations are presented in Hijmans et al. (2006). The WorldClim data portal provides only A2 and B2 emission scenarios, for 2020, 2050 and 2080 as calculated for the Third IPCC Assessment Report of the Intergovernmental Panel on Climate Change in 2001.

Both A2 and B2 scenario families describe heterogeneous worlds with a continuously increasing global population and regionally oriented economies; the former with higher population growth rate and slower technological changes; the latter more oriented toward environmental protection and social equity (Intergovernmental Panel on Climate Change 2000). In the present work we used 'current', A2 and B2 available scenarios as calculated by the Hadley Centre for Climate Prediction and Research.

A central coordinate was determined for each of the seven chosen sites and the referred calculated bioclimatic indices were then collected for each of these sites (see Table 1). A bioclimatic envelope was defined for each site as explained below, taking into account the three indices proposed in the World Bioclimatic Classification of Rivas-Martínez (WBCRM, Rivas-Martínez 2007):

CTI results from the sum of annual mean temperature, the mean maximum temperature of the coldest month and the mean minimum temperature of the coldest month (Rivas-

Table 1 Coordinates (ETRS89) of the seven sites and respective bioclimatic indices for 'current' conditions (1950-2000) according to (Hijmans et al. 2005)

\begin{tabular}{lllllll}
\hline Sites & $\mathrm{X}$ & $\mathrm{Y}$ & $\mathrm{OI}$ & $\mathrm{Ln}(\mathrm{OI})$ & $\mathrm{CTI}$ & SCI \\
\hline JBUTAD & -7.740 & 41.287 & 6.9 & 1.93 & 272.9 & 15.0 \\
JBUP & -8.644 & 41.153 & 6.8 & 1.92 & 332.6 & 10.1 \\
JBUC & -8.421 & 40.206 & 4.9 & 1.60 & 359.8 & 12.3 \\
JBA & -9.201 & 38.706 & 3.7 & 1.32 & 388.2 & 10.9 \\
ESACB & -7.461 & 39.822 & 4.5 & 1.50 & 320.4 & 16.5 \\
UE & -8.014 & 38.531 & 3.2 & 1.15 & 361.3 & 13.6 \\
UA & -7.924 & 37.027 & 2.4 & 0.89 & 408.5 & 11.6 \\
\hline
\end{tabular}

For explanations of the abbreviations, see text 
Fig. 1 Schematic representation of the bioclimatic envelope used. The central point corresponds to the central coordinate (CTI, $\ln (\mathrm{OI})$ and SCI) for each botanical collection, as calculated by Hijmans et al. (2005) for 'current' conditions

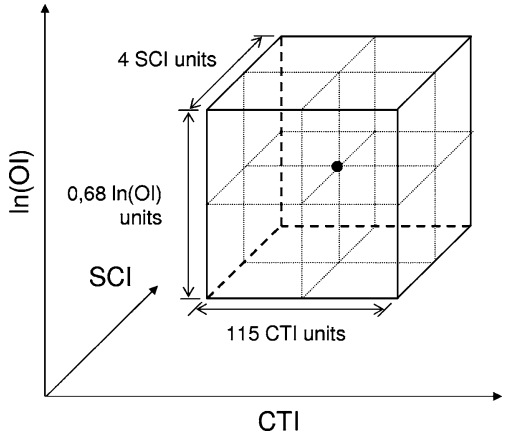

Martínez 2007), thereby incorporating information about low temperatures, which are known to be of great relevance for plant distributions (Woodward and Williams 1987). Rivas-Martínez (2007) defines thermotypes as classes of CTI since, generally, the change in CTI between each thermotype is enough to produce a considerable change in vegetation. On average, each thermotype class corresponds to an interval of 115 of CTI. Consequently, for the establishment of the bioclimatic envelope 57.5 was added and subtracted to the value of CTI found, for the 'current' conditions at each site.

$\mathrm{OI}$ is calculated dividing positive precipitation (sum of mean monthly precipitations, for months with positive mean temperature) by positive temperature (sum of the positive monthly mean temperatures) (Rivas-Martínez 2007). The ombrothermic index is used in the WBCRM to define ombrotypes. The ombrotype classes have an exponential adjustment $\left(R^{2}=0.9961\right)$, therefore, in order to define the environmental envelope, the natural logarithm of OI was used instead. Each ombrotype corresponds to a mean interval of 0.68 of $\ln (\mathrm{OI})$ (see Rivas-Martínez 2007). This value was used to define the range of the bioclimatic envelope around the OI values found for the 'current' conditions at each site.

Similarly, SCI (the difference between mean temperatures of the hottest and the coldest months) is used to define continentality classes by Rivas-Martínez (2007). Each continentality subtype, of those present in the Iberian Peninsula, covers four units of SCI, on average. This value was also used to define the range of the bioclimatic envelope.

In conclusion, for each botanic garden an original bioclimatic envelope of $\pm 57.5 \mathrm{CTI}$, $\pm 0.34 \ln (\mathrm{OI})$ and $\pm 2 \mathrm{SCI}$ was defined for 'current' climatic conditions, as calculated by Hijmans et al. (2005) (see Fig. 1).

These bioclimatic envelopes are a rectilinear or boxcar type (see Guisan and Zimmermann 2000) similar to BIOCLIM proposed by Nix (1986) and Busby (1991), although not using the percentiles proposed by those authors in order to improve species distribution modelling results.

Each defined envelope was then located spatially using the maps of bioclimatic indices calculated both for 'current' conditions and for the referred future climate change scenarios using simple Map Algebra instructions within ESRI ArcMap ${ }^{\mathrm{TM}} 9.2$ SP5 geographical information system.

\section{Results}

Figure 2 shows the spatial distribution of the defined bioclimatic envelopes for 'current' and for future $(2020,2050,2080)$ conditions as predicted according to the A2 emission 


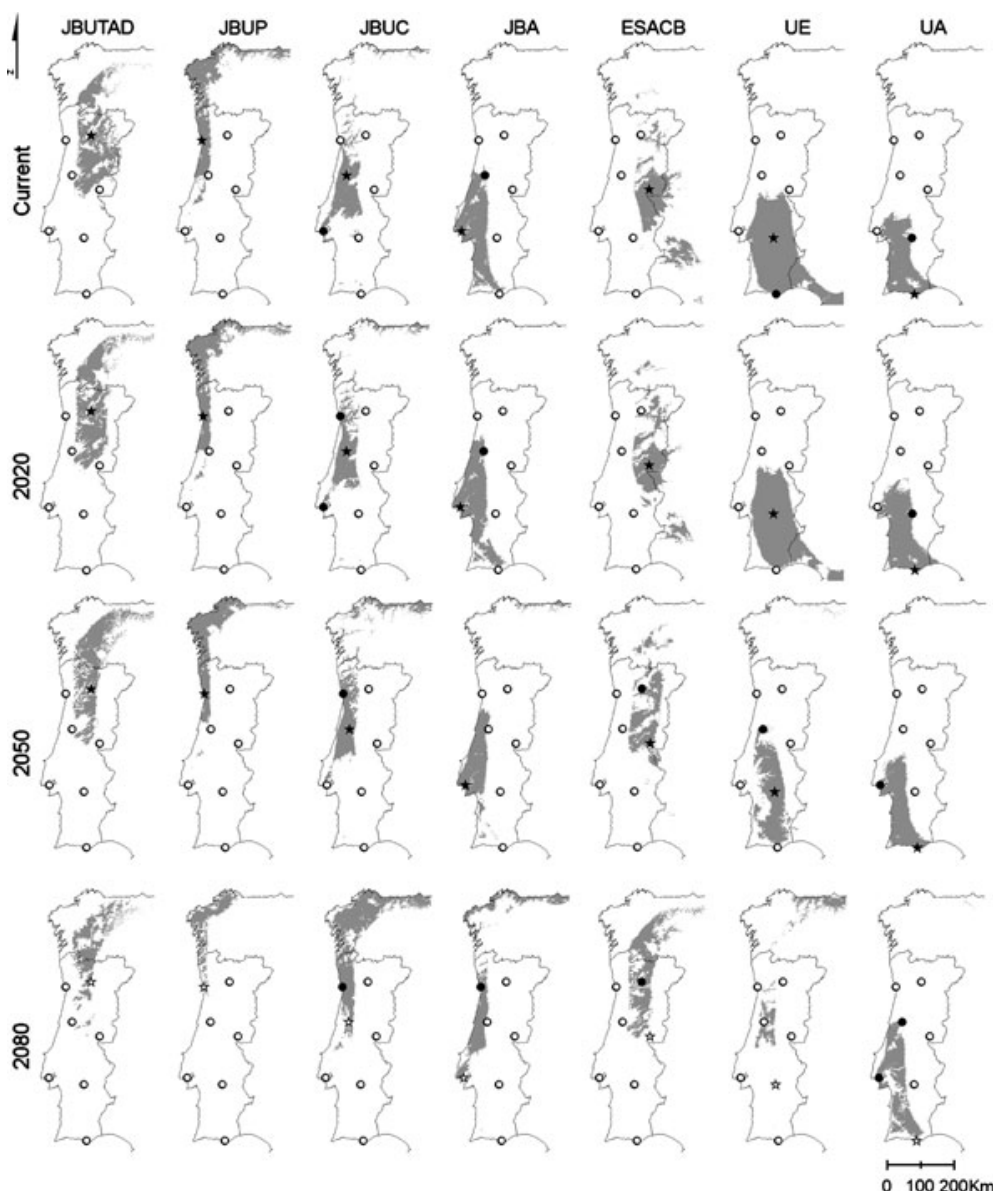

Fig. 2 Spatial representation of the defined bioclimatic envelopes (grey areas) for each considered botanical collection for 'current' conditions and for future scenario A2. Stars represent the botanical collection in question (within each column). Circles represent all the other botanical collections. Symbols are filled when included in the predicted areas, otherwise are empty. ETRS89 projected according to the Instituto Geográfico Português parameters. ${ }^{\odot}$ EuroGeographics for the administrative boundaries

scenario. In Fig. 3, the spatial distribution of the same bioclimatic envelopes for 'current' and for future $(2020,2050,2080)$ conditions under the scenario B2 are shown.

By evaluating Fig. 2, which refers to scenario A2, it is possible to ascertain that all studied sites stay within the predicted areas of their original bioclimatic envelopes until 2050. In contrast, all of them are outside the predicted areas in 2080. Conversely, in Fig. 3 it is possible to observe that all studied sites remained within their original bioclimatic envelope until 2080, although some of them occupy a marginal position in the predicted areas in 2080.

Observing which botanical collections are included in each predicted area enable the definition of knowledge-transfer paths among institutions (e.g. better-suited species, specific cultivation techniques for each species, watering/drainage needs, etc.). An exercise of knowledge-transfer between the studied sites for the A2 scenario was performed (see Fig. 4) using the following rules: (1) a knowledge-transfer arrow was added to the graph 


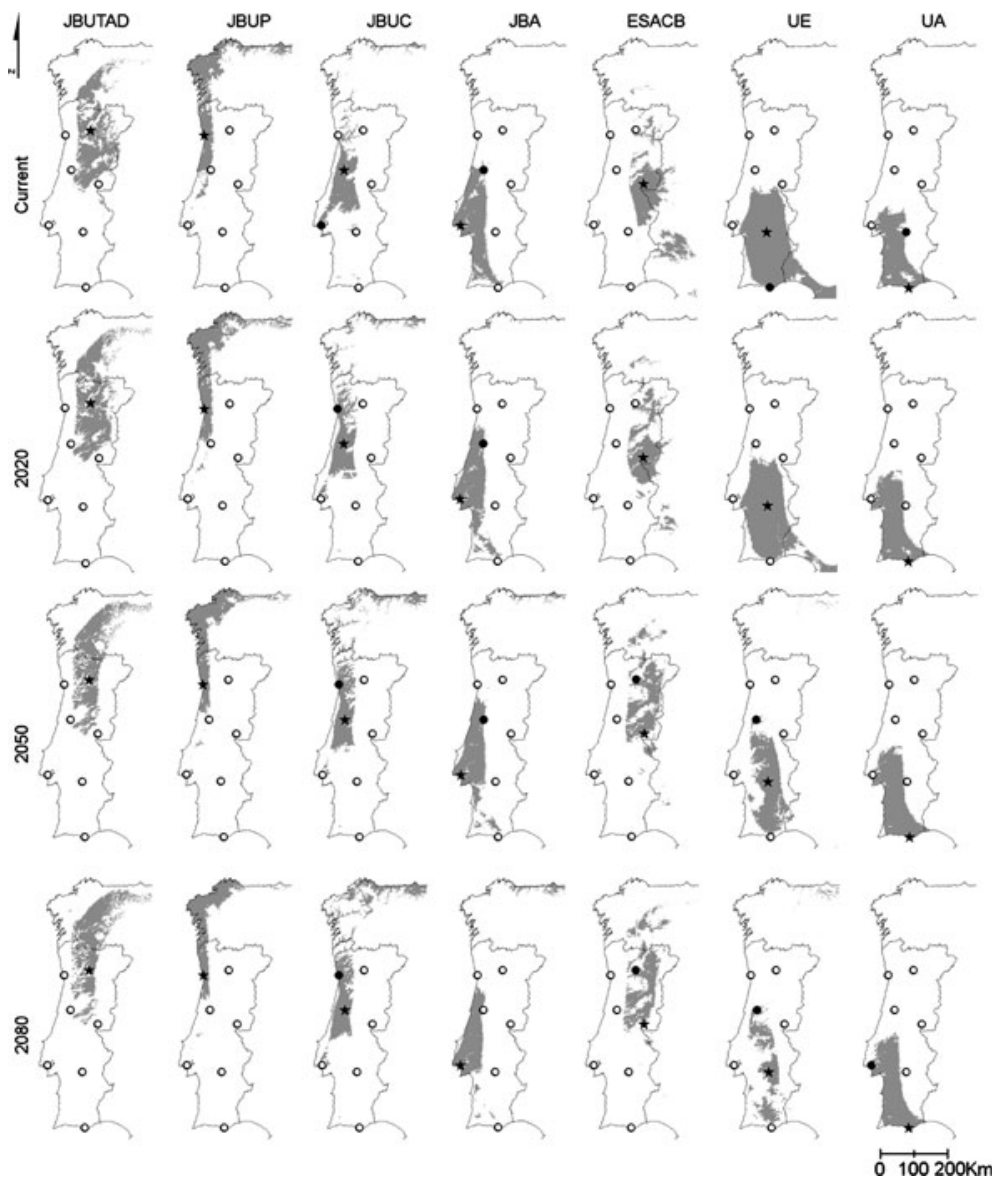

Fig. 3 Spatial representation of the defined bioclimatic envelopes (grey areas) for each considered botanical collection for 'current' conditions and for future scenario B2. Stars represent the botanical collection in question (within each column). Circles represent all the other botanical collections. Symbols are filled when included in the predicted areas, otherwise are empty. ETRS 89 projected according to the Instituto Geográfico Português parameters. ${ }^{\circledR}$ EuroGeographics for the administrative boundaries

when the successive predicted area included a new site (in relation to 'current' conditions); (2) a knowledge-transfer arrow was also added between a site and itself, but only if the site was included in the successive predicted area. Considering the B2 scenario all sites remain inside their original bioclimatic envelope until 2080, thus setting knowledge-transfer paths becomes less relevant. Considering the obtained knowledge-transfer graph (Fig. 4), it is worth realizing that for JBUTAD, JBUP and UE it was not possible to establish any knowledge-transfer path between 2050 and 2080 for the A2 scenario. That was expected for JBUTAD and JBUP as both of these sites are located in the northern part of mainland Portugal, and the expected northward shift of the depicted areas could determine the displacement of present climatic condition to the Spanish region of Galicia. The case of Évora (UE) is more prominent: its central position in the environmentally homogeneous southern Portugal resulted in the largest area depicted for 'current' conditions; however, this area is extremely reduced by 2080 (also according to the B2 scenario predictions), and the expected northward shift seems much greater than for other studied sites. 


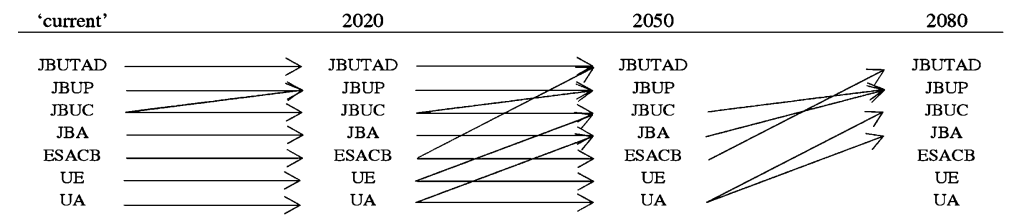

Fig. 4 Knowledge-transfer paths between botanical collections according to the A2 emission scenario predictions

\section{Discussion}

Both A2 and B2 scenarios showed area shifts towards higher latitudes, although greater shifts can be seen for the A2 predictions. Such shifts were expected and are consistent with the well-studied responses of woody species to Quaternary climate (Davis and Shaw 2001). Additionally, both studied scenarios also present a great progressive reduction in the area associated with the botanical collections of UE, leading to the notion that such combinations of environmental variables will be less frequent in future, probably corresponding to a "disappearing climate" (as studied by Williams et al. (2007) at the global scale), at least in the western part of the Iberian Peninsula. Special attention should be paid, in future, to the associated flora of this region, as the referred area reduction can commit present species to extinction (Thomas et al. 2004).

According to the IPCC A2 scenario, all considered botanical collections will be outside the predefined bioclimatic neighbourhood by 2080, while under the B2 scenario, all sites remain within that neighbourhood, although sometimes marginally so. Therefore, the implementation of global sustainability measures as considered in the B2 scenario family is of great importance in order to significantly delay the impacts of climate change, thereby providing extra time for the required adjustments of the outdoor regional living plant collections. In the near future, botanical collections, which are normally fixed to a specific area, should use regional climate change scenarios when selecting species for their regional living plant collections. The use of such scenarios would increase not only the success and persistence of their collections, but also the success of their ex situ conservation programmes. Simultaneously, environmental envelope models can help finding ways of knowledge transmission in order to facilitate such adjustments, as well as managed migration. The urgency of biodiversity conservation calls for real-time monitoring of changes, for the accomplishment of well-defined targets and for the optimization of prioritization (such as proposed by Farnsworth et al. 2006) in order to attain biodiversity persistence.

Acknowledgement We would like to thank two anonymous reviewers as well as Johan Kotze for their comments and suggestions that undoubtedly improved the readability, consistency and structure of the manuscript.

\section{References}

Appell D (2009) Escape from the killing fields. Sci Am 300:78-80

Araújo MB, Luoto M (2007) The importance of biotic interactions for modelling species distributions under climate change. Glob Ecol Biogeogr 16:743-753

Araújo MB, Rahbek C (2006) How does climate change affect biodiversity? Science 313:1396-1397 
Araújo MB, Pearson RG, Thuiller W et al (2005a) Validation of species-climate impact models under climate change. Glob Change Biol 11:1504-1513

Araújo MB, Whittaker RJ, Ladle RJ et al (2005b) Reducing uncertainty in projections of extinction risk from climate change. Glob Ecol Biogeogr 14:529-538

Botkin DB, Saxe H, Araújo MB et al (2007) Forecasting the effects of global warming on biodiversity. Bioscience 57:227-236

Box EO (1981) Macroclimate and plant forms: an introduction to predictive modelling in phytogeography. Junk, The Hague

Brook BW, Sodhi NS, Bradshaw CJA (2008) Synergies among extinction drivers under global change. Trends Ecol Evol 23:453-460

Busby JR (1991) BIOCLIM-a bioclimate analysis and prediction system. In: Margules CR, Austin MP (eds) Nature conservation: cost effective biological surveys and data analysis. CSIRO, East Melbourne

Chapin FS III, Danell K, Elmqvist T et al (2007) Managing climate change impacts to enhance the resilience and sustainability of Fennoscandian forests. Ambio 36:528-533

Davis MB, Shaw RG (2001) Range shifts and adaptive responses to quaternary climate change. Science 292:673-679

Farnsworth E, Klionsky S, Brumback W et al (2006) A set of simple decision matrices for prioritizing collection of rare plant species for ex situ conservation. Biol Conserv 128:1-12

Felton A, Fischer J, Lindenmayer DB et al (2009) Climate change, conservation and management: an assessment of the peer-reviewed scientific journal literature. Biodivers Conserv 18:2243-2253

Fitzpatrick MC, Hargrove WW (2009) The projection of species distribution models and the problem of non-analog climate. Biodivers Conserv 18:2255-2261

Gavilán R (2005) The use of climatic parameters and indices in vegetation distribution. A case study in the Spanish Sistema Central. Int J Biometeorol 50:111-120

Guerrant EOJ, Pavlik BM (1997) Reintroduction of rare plants: genetics, demography, and the role of ex situ conservation methods. In: Fiedler PL, Kareiva PM (eds) Conservation biology for the coming decade. Chapman \& Hall, New York

Guisan A, Zimmermann NE (2000) Predictive habitat distribution models in ecology. Ecol Modell 135: $147-186$

Hampe A (2004) Bioclimate envelope models: what they detect and what they hide. Glob Ecol Biogeogr 13:469-471

Hannah L (2008) Protected areas and climate change. Ann N Y Acad Sci 1134:201-212

Hijmans RJ, Cameron SE, Parra JL et al (2005) Very high resolution interpolated climate surfaces for global land areas. Int J Climatol 25:1965-1978

Hijmans RJ, Cameron SE, Parra JL et al (2006) WORLDCLIM. http://www.worldclim.org. Cited 31 May 2009

Holmes B (2007) Assisted migration: helping nature to relocate. New Sci 196:46-49

Hunter MLJ (2007) Climate change and moving species: furthering the debate on assisted colonization. Conserv Biol 21:1356-1358

Intergovernmental Panel on Climate Change (2000) IPCC special report emissions scenarios: summary for policymakers. Intergovernmental Panel on Climate Change. http://www1.ipcc.ch/pdf/special-reports/ spm/sres-en.pdf. Cited 26 Nov 2009

McLachlan JS, Hellmann JJ, Schwartz MW (2007) A framework for debate of assisted migration in an era of climate change. Conserv Biol 21:297-302

Mueller JM, Hellmann JJ (2008) An assessment of invasion risk from assisted migration. Conserv Biol 22:562-567

Nix HA (1986) A biogeographic analysis of Australian elapid snakes. In: Longmore R (ed) Atlas of elapid snakes of Australia. Australian Government Publishing Service, Canberra

Pearson RG, Dawson TP (2003) Predicting the impacts of climate change on the distribution of species: are bioclimate envelope models useful? Glob Ecol Biogeogr 12:361-371

Pearson RG, Dawson TP (2004) Bioclimate envelope models: what they detect and what they hideresponse to Hampe (2004). Glob Ecol Biogeogr 13:471-473

Pyšek P, Lambdon PW, Arianoutsou M et al (2009) Alien vascular plants of Europe. In: Handbook of alien species in Europe. Invading nature: Springer series in invasion ecology, vol 3. Springer, Dordrecht, pp 43-61

Richardson DM, Hellmann JJ, McLachlan JS et al (2009) Multidimensional evaluation of managed relocation. Proc Natl Acad Sci USA 106:9721-9724

Rivas-Martínez S (2007) Mapa de series, geoseries y geopermaseries de vegetación de España. Itinera Geobotanica 17:5-436 
Secretariat of the Convention on Biological Diversity (2003) Global strategy for plant conservation. http://www.bgci.org/files/All/Key_Publications/globalstrategyeng223.pdf. Cited 30 July 2009

Thomas CD, Cameron A, Green RE et al (2004) Extinction risk from climate change. Nature 427(6970): $145-148$

Thuiller W, Lavorel S, Araújo MB et al (2005) Climate change threats to plant diversity in Europe. Proc Natl Acad Sci USA 102:8245-8250

Thuiller W, Albert C, Araújo MB et al (2008) Predicting global change impacts on plant species' distributions: future challenges. Perspect Plant Ecol Evol Syst 9:137-152

Williams JW, Jackson ST, Kutzbach JE (2007) Projected distributions of novel and disappearing climates by 2100 AD. Proc Natl Acad Sci USA 104:5738-5742

Woodward FI, Williams BG (1987) Climate and plant distribution at global and local scales. Vegetatio 69:189-197 
Reproduced with permission of the copyright owner. Further reproduction prohibited without permission. 